\title{
PENERAPAN BAHAN AJAR MATEMATIKA BERBASIS REALISTIC MATHEMATICS EDUCATION (RME) TERHADAP KEMAMPUAN BERPIKIR KREATIF MATEMATIS
}

\author{
${ }^{1}$ Yesi Lusiana Septia \\ ${ }^{1}$ Pendidikan Matematika, Fakultas Keguruan dan Ilmu Pendidikan, Universitas Muhammadiyah Sukabumi \\ yesilusianasept@gmail.com
}

\begin{abstract}
ABSTRAK
Tujuan dalam penelitian ini adalah untuk mengkaji kemampuan berfikir kreatif matematis siswa melalui penerapan bahan ajar matematika yang bebasis RME. Metode yang digunakan pada penelitian ini adalah metode kualitatif dengan jenis penelitian studi kepustakaan. Dalam Penerapan model pembelajaran RME, suatu kegiatan pembelajaran dihubungkan dengan kehidupan sehari-hari. Sehingga didapatkan hasil bahwa penggunaan bahan ajar matematika berbasis Realistic mathematics Education (RME) berpengaruh positif terhadap kemampuan berfikir kreatif matematis siswa.
\end{abstract}

Kata kunci: Realistic Mathematics Education (RME), Bahan Ajar Matematika Berbasis RME, Kemampuan Berpikir Kreatif.

\section{PENDAHULUAN}

Tujuan Pendidikan Nasional Menurut Undang- Undang Nomor 20 tahun 2003 pasal 3, yaitu mengembangkan potensi peserta didik agar menjadi manusia yang beriman dan bertakwa kepada Tuhan Yang Maha Esa, berakhlak mulia, sehat, berilmu, cakap, kreatif, mandiri, dan menjadi warga negara yang demokratis serta bertanggung jawab. Demi tercapainya tujuan pendidikan tersebut, maka guru mempunyai tanggung jawab salah satunya yaitu mengembangkan bahan ajar. Setiap bahan ajar yang dikembangkan harus diarahkan untuk mengembangkan kemampuan siswa, salah satunya yaitu kemampuan berpikir kreatif yang menjadi kompeten dalam pembelajaran matematika. Maka dari itu, matematika sangat penting untuk dipelajari karena dengan belajar matematika akan membuat siswa terlatih dalam menyelesaikan masalah secara sistematis, kritis, logis, kreatif (Komarudin et al., 2014; Komarudin \& Permana, 2019).

Menurut Martin (2009), kemampuan berpikir kreatif adalah kemampuan untuk menghasilkan ide atau cara baru dalam menghasilkan suatu produk (Komarudin et al., 2014; KOMARUDIN et al., 2020; Puspita et al., 2018). Berfikir kreatif juga termasuk ke dalam aspek kognitif. Namun Kenyataan di lapangan, dalam proses pembelajaran matematika masih menerapkan model yang lama, dimana seorang guru hanya sekedar menjelaskan rumus yang ada, memberi contoh soal, kemudian memberikan latihan soal. Sehingga, dengan metode seperti itu perkembangan kognitif pada siswa tidak berkembang dan membuat siswa kesulitan dalam memahami matematika yang abstrak. Sementara itu, matematika sangat lekat dalam kehidupan sehari-hari. Oleh karena itu, seorang guru diharuskan mampu memberikan pemahaman yang bukan hanya sekedar penjelasan materi tetapi harus bisa memberikan contoh nyata dalam kehidupan sehari-hari. Salah satu metode belajar yang dapat memenuhi masalah di atas adalah RME. Realistic Mathematics Education (RME) merupakan konsep pembelajaran yang menjadikan peserta didik menjadi lebih aktif dalam kegiatan belajar mengajar.

Dalam kaitan permasalahan di atas, maka di terapkan pembelajaran matematika yang menggunakan bahan ajar matematika yang berbasis Realistic Mathematics Education (RME) yang bertujuan untuk meningkatkan kemampuan berpikir kreatif matematika siswa. Tujuan dari penelitian ini adalah untuk mengetahui bagaimana efektifitas penerapan bahan ajar matematika berbasis RME terhadap kemampuan berpikir kreatif matematika siswa.

\section{METODE PENELITIAN}

Metode penelitian yang digunakan dalam penelitian ini adalah metode kualitatif dengan jenis penelitian kepustakaan. Penelitian kepustakaan merupakan suatu jenis penelitian yang digunakan dalam pengumpulan informasi dan data secara mendalam melalui berbagai literatur, buku, catatan, serta hasil penelitian sebelumnyayang relevan, untuk mendapatkan jawaban daan landasan teori mengenai masalah yang akan diteliti.

\section{HASIL DAN PEMBAHASAN}

Bahan ajar matematika yang berbasis RME merupakan sekumpulan materi dan soal matematika yang dihubungkan dengan permasalahan yang ada di sekitar, yang bertujuan untuk mempermudah siswa dalam menerima materi. Sehingga, siswa tidak hanya mengandalkan contoh soal yang diberikan seorang 
guru, tetapi mereka dapat menyelesaikannya sendiri secara efektif.

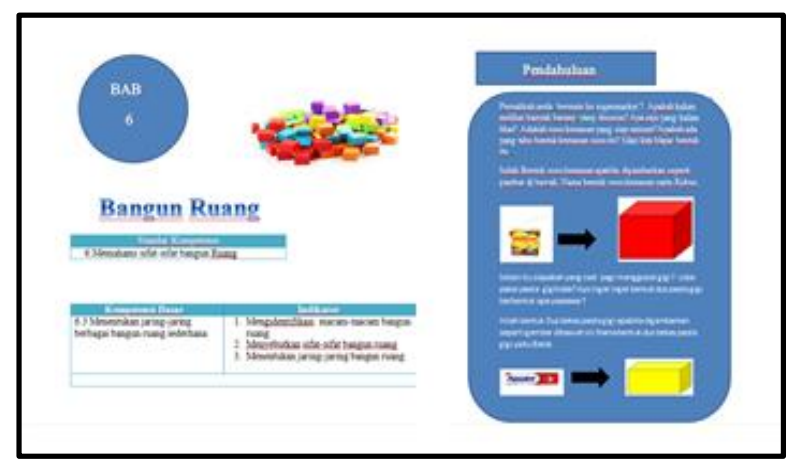

Gambar 1. Layout bahan ajar

Dari gambar diatas dapat dilihat bahwa dalam bahan ajar matematika yang berbasis RME, siswa dikenalkan dan diingatkan tentang bentuk barang yang sering siswa jumpai didalam kehidupan sehari-hari. Dalam gambar di atas salah satunya adalah bentuk susu kemasan siap minum dan bentuk kemasan pasta gigi. Dengan adanya kaitan pembelajaran matematika dengan benda yang sering dijumpai siswa dalam kehidupan sehari- hari, maka siswa akan lebih semangat dan mudah untuk mengingat serta mampu menunjukkan bahwa matematika itu nyata adanya dalam kehidupan. Selain mengenalkan dengan benda yang ada di lingkungan sekitar, dalam bahan ajar ini diberikan permasalahan matematika yang berkaitan dengan kehidupan sehari-hari misalnya sebagai berikut:

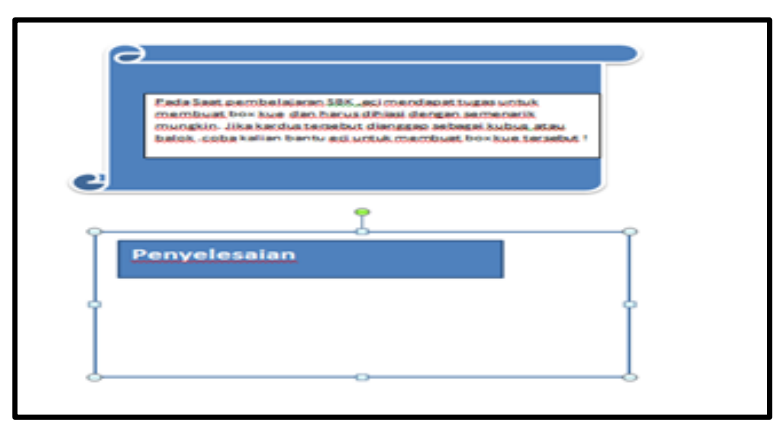

Gambar 2. Contoh permasalahan

\section{DAFTAR PUSTAKA}

Abdurrohim.(2016). "Desain Pembelajaran JaringJaring dan Luas Permukaan Kubus Menggunakan Media Kubus Guling Berwarna.”. jurnal Prosiding Seminar Nasional Matematika dan Terapannya 2016: Universitas Islam Darul Ulum Lamongan

Ayu, Chandra \& Desi.(2018). "Realistic Mathematics Education (RME) Berbantuan Literature Matematis untuk Meningkatkan Kemampuan Berfikir Kreatif Matematis Siswa Sekolah Dasar".
Siswa diberi masalah yang ada kaitannya dengan kehidupan sehari-hari. Berdasarkan gambar di atas siswa di beri masalah yaitu dengan cara untuk membuat box kue yang dianggap berbentuk kubus atau balok yang harus dihias semenarik mungkin. Sebelum siswa membuat box kue, siswa harus tahu terlebih dahulu tentang jaring-jaring kubus ataupun balok. Setelah itu, siswa mengembangkan nya dengan menggambarkan jaring-jaring kubus-baloknya. Hal ini membuat siswa lebih semangat dalam belajar matematika .karena pada dasarnya jaring-jaring balok kurang di pahami siswa.

\section{PENUTUP}

Simpulan

Berdasarkan hasil penelitian, dapat disimpulkan bahwa penerapan bahan ajar yang berbasis Realistic Mathematics Education (RME) diharapkan dapat meningkatkan kemampuan berpikir kreatif matematis siswa, hal ini disebabkan karena:

1. Bahan ajar tersebut memfasislitasi siswa dalam mengkonstruksi pengetahuan meraka.

2. Siswa diberikan permasalahan matematika yang berkaitan dengan benda-benda yang terdapat di lingkungan sekitar.

3. Siswa menjadi termotivasi dan berperan aktif dalam permasalahan matematika, karena pembelajaran dihubungkan dengan kehidupan sehari-hari.

\section{Saran}

Dari hasil penelitian ini diharapkan dapat digunakan sebagai referensi dalam meningkatkan kualitas pembelajaran matematika di sekolah. Selain itu, diharapkan terdapat penelitian lanjutan terkait penerapan bahan ajar matematika berbasis Realistic Mathematics Education (RME) untuk kemampuan matematis yang lainnya.

Program Studi Pendidikan Matematika: Universitas Pendidikan Indonesia

Ekasatya.(2016). "Makna Realistic dalam RME dan PMRI". FKIP: STKIP Garut

Komarudin, K., \& Permana, P. T. (2019). LKPD Berbasis Scientific Approach Terhadap Kemampuan Pemecahan Masalah Matematis Peserta Didik Sekolah Dasar. TERAMPIL: Jurnal Pendidikan Dan Pembelajaran Dasar, 6(1), 7991. https://doi.org/10.24042/terampil.v6i1.4385 
KOMARUDIN, K., SUHERMAN, S., PUSPITA, L., ARRAFIANSYAH, R., \& HASANAH, U. (2020). Program course lab 2.4 mathematics learning media for increasing of creativity domain at Higher Order Thinking Skills (HOTS). Journal of Gifted Education and Creativity, 7(3), 131-136.

Komarudin, K., Sujadi, I., \& Kusmayadi, T. A. (2014). Proses Berpikir Kreatif Siswa SMP Dalam Pengajuan Masalah Matematikaditinjau Dari Gaya Kognitif Siswa (Studi Kasus Pada Siswa Kelas Viii-h SMP Negeri 1 Sukoharjo Tahun Pelajaran 2012/2013). Jurnal Pembelajaran Matematika, 2(1).

Puspita, L., Supriadi, N., \& Pangestika, A. D. (2018). Pengaruh Model Pembelajaran Creative Problem Solving (Cps) Disertai Teknik Diagram Vee Terhadap Keterampilan Berpikir Kreatif Peserta Didik Materi Fungi Kelas X MAN 2 BANDAR LAMPUNG. Biosfer: Jurnal Tadris Biologi, 9(1), 01-12.
Lestari July, Oyon Haki Pranata, dkk. (2018). "Desain Didaktis Jaring-Jaring Kubus dan Balok untuk Mengembangkan Kemampuan Berpikir Kreatif Siswa”. Jurnal Ilmiah Pendidikan Guru Sekolah dasar:5 (1), Hal. 263-273

Mahmud, Ali. (2010). "Mengukur Kemampuan Berpikir Kreatif Matematis". FKIP: Universitas Negeri Yogyakarta

Pratama, Aditya. (2019).’'Upaya Meningkatkan Hasil Belajar Matematika Menggunakan Media Kantong Bilangan pada Siswa Kelas I SD Negeri 1 Karangsari, Kulon Progo". Fakultas Ilmu Pendidikan. Program Studi Pendidikan Sekolah Dasar: Universitas Negeri Yogyakarta

Sumianto.(2018). "Penerapan Pendekatan Matematika Realistik (PMR) untuk Meningkatkan Hasil Belajar Matematika Siswa Kelas V Alazim SDIT Raudhatur Rahmah”. Jurnal Basicedu : 2 (1) Hal. 49-56 